\title{
Improve Accounting For Cost Allocations From Support To Revenue-Generating Departments With The Reciprocal Method
}

\author{
Dennis Togo, University of New Mexico, USA
}

\begin{abstract}
The best accounting method for allocating the cost of support departments to revenue-generating departments is the reciprocal method because it recognizes all services provided to other departments. Hence, the reciprocal method better captures the full cost of services consumed by revenue-generating departments. Yet, many healthcare organizations continue to use the direct or step-down methods because the reciprocal method requires solving algebraic simultaneous equations in the allocation of many support departments. This educational resource removes the difficulty associated with the reciprocal method with a matrix approach that is demonstrated with an example. From information provided for any cost allocation method, three spreadsheet matrix commands formulate the set of linear equations for reciprocated costs of support departments, solve for the reciprocated costs, and then allocate the reciprocated costs to both support departments and revenue-generating departments.
\end{abstract}

Keywords: Reciprocal; Allocations; Matrix

\section{INTRODUCTION}

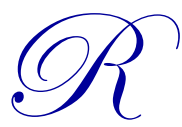

evenue-generating departments of healthcare organizations use services and products provided by support departments in fulfilling work requested by medical professionals. While some support department costs are easily traceable to the services provided, the remaining costs of support departments are allocated to user departments. As noted in the accounting literature, the main benefit of allocating support department costs is more accurate product or service cost information, which leads to improved decisionmaking and improved financial reporting (Horngren, Datar, \& Rajan, 2012).

Three common pro-rata methods for allocating support department costs to revenue-generating departments are reciprocal, direct, and step-down. The differences among the three methods focus on the recognition of support services to other support departments. The reciprocal method for allocating support department costs is preferred as all services provided by support departments to other support departments are recognized. The step-down method recognizes only partial services as support departments previously allocated (i.e., closed) cannot receive costs from the remaining support departments. Furthermore, the order in which support departments are closed under the stepdown method impacts the costs allocated to revenue-generating departments. The direct method recognizes no support services provided to other support departments as support costs are allocated only to revenue-generating departments.

The three methods lead to different amounts allocated from the support department to the overhead costs of revenue-generating departments. Costs allocated by support departments can have a significant impact on healthcare organizations. For example, cost reimbursement contracts and the setting of fees for services provided are influenced by cost allocations of support departments. Furthermore, the allocations become more important with expected increases in support costs and support departments.

Even though the reciprocal method is superior to the common step-down and direct methods, its adoption has been curtailed by mathematical difficulties in solving simultaneous equations. Specifically, a hospital having $n$ 
support departments will require the solving of $n$ simultaneous equations. Facing such a challenging task, it is no wonder then that the step-down method is the most adopted method of allocating support department costs to other departments. This educational resource illustrates how three spreadsheet matrix functions will simplify the use of the preferred reciprocal method to allocate support department costs.

\section{EXAMPLE FOR A MATRIX APPROACH TO RECIPROCAL COST ALLOCATIONS}

\section{Departmental Data - Panel A of Table 1}

The $\$ 5,000,000$ total cost for five support departments - A, B, C, D, and E - and two revenue-generating departments - X and Y - is presented in Panel A: Input Data of Table 1. In addition, the percentage of services provided by the five support departments to all other departments is presented with a $5 \mathrm{X} 7|\mathrm{P}|$ percentage matrix of 5 rows and 7 columns. The $5 \times 7|\mathrm{P}|$ matrix can be expressed as $\left(\mathrm{P}_{1,1}: \mathrm{P}_{5,7}\right)$, which identifies the array by its opposite corner locations of $1^{\text {st }}$ row and $1^{\text {st }}$ column and that of $5^{\text {th }}$ row and $7^{\text {th }}$ column. As an example of information provided, support Department $\mathrm{A}$, which has costs of $\$ 700,000$, provides services to Departments B, C, D, E, X, and $\mathrm{Y}$ of $0.10,0.08,0.07,0.05,0.30$, and 0.40 , respectively. The sum of services provided by Department $\mathrm{A}$ is equal to 1.00. The -1.00 for Department A represents the services that will be allocated to other departments. Hence, the total for support Department A is equal to 0.00 .

Table 1: Reciprocal Method

\begin{tabular}{|c|c|c|c|c|c|c|c|c|}
\hline \multicolumn{4}{|c|}{ Panel A: Departmental Data } & \multirow[b]{2}{*}{ Dept D } & \multirow[b]{2}{*}{ Dept E } & \multirow[b]{2}{*}{ Dept X } & \multirow[b]{2}{*}{ Dept Y } & \multirow[b]{2}{*}{ Total } \\
\hline & Dept A & Dept B & Dept C & & & & & \\
\hline Costs: & 700,000 & 500,000 & 400,000 & 300,000 & 100,000 & $2,000,000$ & $1,000,000$ & $5,000,000$ \\
\hline Support by & \multicolumn{8}{|c|}{$\mathbf{P}$} \\
\hline Dept A & -1.00 & 0.10 & 0.08 & 0.07 & 0.05 & 0.30 & 0.4 & 0.00 \\
\hline Dept B & 0.09 & -1.00 & 0.06 & 0.06 & 0.04 & 0.50 & 0.25 & 0.00 \\
\hline Dept C & 0.08 & 0.05 & -1.00 & 0.04 & 0.03 & 0.60 & 0.20 & 0.00 \\
\hline Dept D & 0.10 & 0.05 & 0.15 & -1.00 & 0.10 & 0.35 & 0.25 & 0.00 \\
\hline Dept E & 0.14 & 0.10 & 0.08 & 0.08 & -1.00 & 0.30 & 0.30 & 0.00 \\
\hline \multicolumn{9}{|c|}{ Panel B: Simultaneous Equation $|S| x|X|=|K| \quad|S|=-\operatorname{TRANSPOSE}\left(P_{11}: P_{5,5}\right)$} \\
\hline \multicolumn{6}{|c|}{$\underline{\mathbf{S}}$} & $\underline{\mathbf{x}}$ & $=$ & $\underline{\mathbf{K}}$ \\
\hline Dept A & +1.00 & -0.09 & -0.08 & -.10 & -0.14 & \multirow{5}{*}{$\mathrm{x}$} & & 700,000 \\
\hline Dept B & -0.10 & +1.00 & -0.05 & -0.05 & -0.10 & & & 500,000 \\
\hline Dept C & -0.08 & -0.06 & +1.00 & -0.15 & -0.08 & & $=$ & 400,000 \\
\hline Dept D & -0.07 & -0.06 & -0.04 & +1.00 & -0.08 & & & 300,000 \\
\hline Dept E & -0.05 & -0.04 & -0.03 & -0.10 & +1.00 & & & 100,000 \\
\hline \multicolumn{9}{|c|}{ Panel C: Reciprocated Costs $|X|$ and Diagonal $|D|$ Matrices } \\
\hline & $\underline{\mathbf{X}}$ & \multicolumn{7}{|c|}{ 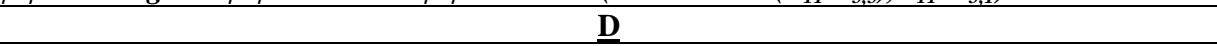 } \\
\hline Dept A & $88 \overline{4,459}$ & & 884,459 & 0 & $\overline{0}$ & 0 & 0 & \\
\hline Dept B & 663,757 & & 0 & 663,757 & 0 & 0 & 0 & \\
\hline Dept C & 595,860 & & 0 & 0 & 595,860 & 0 & 0 & \\
\hline Dept D & 444,218 & & 0 & 0 & 0 & 444,218 & 0 & \\
\hline Dept E & 233,071 & & 0 & 0 & 0 & 0 & 223,071 & \\
\hline \multicolumn{9}{|c|}{ Panel D: Reciprocated Cost Allocations $\quad|A|=M M U L T\left(D_{1,1}: D_{5,5}, P_{1,1}: P_{5,7}\right)$} \\
\hline & Dept A & Dept B & Dept C & Dept D & Dept E & Dept X & Dept Y & Total \\
\hline Costs: & 700,000 & 500,000 & 400,000 & 300,000 & 100,000 & $2,000,000$ & $1,000,000$ & $5,000,000$ \\
\hline Allocations & & & & $\underline{\mathbf{A}}$ & & & & \\
\hline Dept A & $-884,459$ & 88,446 & 70,757 & $61, \overline{9} 12$ & 44,223 & 265,338 & 353,783 & 0 \\
\hline Dept B & 59,738 & $-663,757$ & 39,825 & 39,825 & 26,550 & 331,878 & 165,939 & 0 \\
\hline Dept C & 47,669 & 29,793 & $-595,860$ & 23,834 & 17,876 & 357,516 & 119,172 & 0 \\
\hline Dept D & 44,422 & 22,211 & 66,633 & $-444,218$ & 44,422 & 155,476 & 111,054 & 0 \\
\hline Dept E & 32,630 & 23,307 & 18,646 & 18,646 & $-233,071$ & 69,921 & 69,921 & 0 \\
\hline Total & 0 & 0 & 0 & 0 & 0 & $3,180,130$ & $1,819,870$ & $5,000,000$ \\
\hline
\end{tabular}




\section{Matrix Simultaneous Equation - Panel B of Table 1}

Simultaneous equations must be formulated for the reciprocal method of support department cost allocations. In formulating the simultaneous equations using matrices, the variables $\mathrm{A}, \mathrm{B}, \mathrm{C}, \mathrm{D}$, and $\mathrm{E}$ are first defined as the reciprocated costs of their related support departments. The set of five simultaneous equations is formed with the matrix multiplication $|\mathrm{S}| \mathrm{x}|\mathrm{X}|=|\mathrm{K}|$ shown in Panel B of Table 1. With Dept $\mathrm{A}$ as an example, its simultaneous equation is formed by multiplying the first row of the $|S|$ matrix with the columnar $|X|$ matrix and setting it equal to 700,000. Hence, the equation for Dept A is +1.00A - 0.09B - 0.08C - 0.10D - 0.14E $=700,000$. This equation for Dept $\mathrm{A}$ can be alternatively presented as $+1.00 \mathrm{~A}=700,000+0.09 \mathrm{~B}+0.08 \mathrm{C}+0.10 \mathrm{D}+0.14 \mathrm{E}$, which is an equation commonly found in accounting textbooks. Both equivalent equations capture the relationship that the reciprocated cost for Dept $A$ is equal to its own cost of $\$ 700,000$ plus reciprocated costs of other support departments allocated to Dept A.

The $|\mathrm{S}|$ matrix represents services among support departments and it can be easily formed as the negative transpose of the array $\left(\mathrm{P}_{1,1}: \mathrm{P}_{5,5}\right)$. After highlighting a $5 \times 5$ output area, the $|\mathrm{S}|$ matrix is generated with the Excel formula =-TRANSPOSE $\left(P_{1,1}: P_{5,5}\right)$ and pressing Ctrl + Shift + Enter keys together. The $5 \mathrm{X} 1|\mathrm{X}|$ matrix is for the sought after reciprocated costs $\mathrm{A}, \mathrm{B}, \mathrm{C}, \mathrm{D}$, and $\mathrm{E}$ of the support departments. The $5 \mathrm{x} 1|\mathrm{~K}|$ matrix is the given individual cost of the five support departments.

\section{Reciprocated Cost Matrix $|\mathbf{X}|$ - Panel C of Table 1}

From the matrix relationship $|\mathrm{S}| \mathrm{x}|\mathrm{X}|=|\mathrm{K}|$ below, the mathematics used to solve for the $|\mathrm{X}|$ matrix requires similarly multiplying both sides of the matrix equation with the matrix $\left|\mathrm{S}^{-1}\right|$ or the inverse of $|\mathrm{S}|$. On the left side of the equation, the $\left|\mathrm{S}^{-1}\right|$ matrix is multiplied with the $|\mathrm{S}|$ matrix and the result is the identity matrix $|\mathrm{I}|$. The identity matrix $|\mathrm{I}|$ multiplied with the $|\mathrm{X}|$ matrix equals just the $|\mathrm{X}|$ matrix on the left side of the equation. Therefore, the $|\mathrm{X}|$ matrix is equal to the $\left|\mathrm{S}^{-1}\right|$ matrix multiplied by the $|\mathrm{K}|$ matrix.

$$
\begin{aligned}
|\mathrm{S}| \mathrm{x}|\mathrm{X}| & =|\mathrm{K}| \\
\left|\mathrm{S}^{-1}\right| \mathrm{x}|\mathrm{S}| \mathrm{x}|\mathrm{X}| & =\left|\mathrm{S}^{-1}\right| \mathrm{x}|\mathrm{K}| \\
|\mathrm{I}| \mathrm{x}|\mathrm{X}| & =\left|\mathrm{S}^{-1}\right| \mathrm{x}|\mathrm{K}| \\
|\mathrm{X}| & =\left|\mathrm{S}^{-1}\right| \mathrm{x}|\mathrm{K}|
\end{aligned}
$$

The $|\mathrm{X}|$ matrix for the reciprocated costs for the five support departments is shown in Panel C of Table 1 . After highlighting a $5 \mathrm{x} 1$ output area, the solution matrix $|\mathrm{X}|$ is generated with the Excel formula $=\operatorname{MMULT}\left(\operatorname{MINVERSE}\left(S_{1,1}: S_{5,5}\right), K_{1,1}: K_{5,1}\right)$ and pressing Ctrl + Shift + Enter keys together. The reciprocated costs for Departments A, B, C, D, and E are $\$ 884,459, \$ 663,757, \$ 595,860, \$ 444,218$, and $\$ 233,071$, respectively. To validate the $\$ 884,459$ reciprocated cost for Department $\mathrm{A}$, refer above to the formula $\mathrm{A}=\$ 700,000+0.09 \mathrm{~B}+0.08 \mathrm{C}$ $+0.10 \mathrm{D}+0.14 \mathrm{E}$. Substituting the reciprocated costs for B, C, D, and E in this formula equals the reciprocated cost of $\mathrm{A}$ or $\$ 884,459=\$ 700,000+0.09(\$ 663,757)+0.08(\$ 595,860)+0.10(\$ 444,218)+0.14(\$ 233,071)$.

\section{Reciprocated Cost Allocations - Panel D of Table 1}

Allocating reciprocated costs to all other departments is performed with the matrix multiplication $|A|=|D|$ $\mathrm{x}|\mathrm{P}|$. The $5 \times 5|\mathrm{D}|$ square matrix commonly used for matrix multiplication is found in Panel C of Table 1. The $|\mathrm{D}|$ matrix has reciprocated costs $\mathrm{A}, \mathrm{B}, \mathrm{C}, \mathrm{D}$, and $\mathrm{E}$ on the diagonal and 0 s everywhere else. The $5 \times 7|\mathrm{P}|$ matrix is from Panel $\mathrm{A}$ and it is the percentages of services provided by support departments to all other departments. The allocated matrix $|\mathrm{A}|$ is found in Panel D: Reciprocated Cost Allocations of Table 1. After highlighting a specified $5 \times 7$ output area as shown in Panel D, the allocated matrix $|\mathrm{A}|$ is generated by entering the EXCEL formula $=\operatorname{MMULT}\left(D_{l, 1}: D_{5,5}, P_{l, 1}: P_{5,7}\right)$ and pressing $\mathrm{Ctrl}+\mathrm{Shift}+$ Enter keys together.

As presented in Panel D, all reciprocated costs for support Departments A, B, C, D, and E have been transferred to the revenue-generating departments. The total for each support department- after the allocation is 0 and the total cost for revenue-generating Departments $\mathrm{X}$ and $\mathrm{Y}$ after the allocation - is equal to the original $\$ 5,000,000$ of both support and revenue-generating departments. In retrospect, the traditional tabular presentation of 
department costs and support services provided has been transfigured into a reciprocal cost allocation table with the use of three Excel commands highlighted above.

\section{SUMMARY}

A matrix approach facilitates support department cost allocations to revenue-generating departments. The preferred reciprocal method that allocates costs of support departments to all users of its services can now be easily performed with matrix functions of spreadsheets. Healthcare accounting relies heavily on cost allocations and the reciprocal method with a matrix approach is positioned for increasing costs and an increasing number of support departments. With more accurate costs for products and services, healthcare financial reporting will be improved and management decision-making will be supported with better cost information.

\section{AUTHOR INFORMATION}

Dennis Togo is a professor of accounting teaching cost/management and information systems courses. He publishes articles highlighting the effective use of accounting information and computers to support management decisions. He earned his accounting doctorate from Arizona State University, and masters and undergraduate accounting degrees, and a mathematics bachelor degree from Brigham Young University. E-mail: $\underline{\text { togo@ } @ u n m . e d u}$

\section{REFERENCES}

1. Horngren, C. T., Datar, S. M., \& Rajan, M. (2012). Cost accounting: A managerial emphasis. Upper Saddle River, NJ: Prentice-Hall. 